
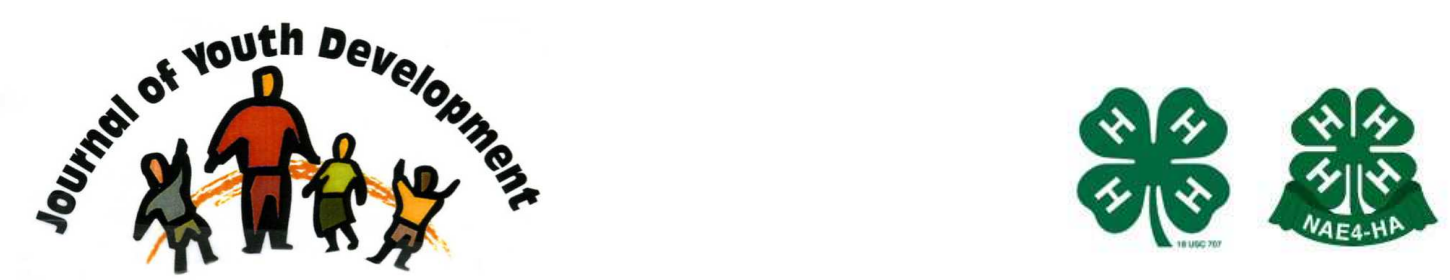

Bridging Research \& Practice

\title{
Using Wordle: A Fun Tool to Show Frequency, Purpose and Direction
}

\author{
Brian Raison \\ Miami County Extension \\ The Ohio State University \\ Troy, $\mathrm{OH}$ \\ raison.1@osu.edu
}




\title{
JOURNAL OF YOUTH DEVELOPMENT \\ bridging research and practice

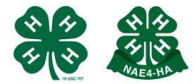

Volume 8, Number 2, Summer 2013

Article 130802RR001

\section{Using Wordle: A Fun Tool to Show Frequency, Purpose and Direction}

Brian Raison

The Ohio State University

\begin{abstract}
Have you ever seen a Wordle? It's that funny jumble of words that are all different sizes and directions. Whether working with youth or adults, Wordles can be a powerful visual tool that can help a group discover key themes, help an individual display main thoughts from a paper, and can provide artwork or visuals for reports, marketing materials, etc. You can make one in less than five minutes. Learn how here.
\end{abstract}

\section{Introduction}

Using Wordle: A Fun Tool to Show Frequency, Purpose and Direction

Most everyone has probably seen a Wordle, even if you didn't know what it was called. It's that funny jumble of words that are all different sizes and directions. But have you ever created one or thought about how you could use one? Whether working with youth or adults, Wordles can be a powerful visual tool. Wordles can:

- help get your point across during a meeting (make one in real time)

- help a group discover key themes from meeting minutes, strategic plans, publications/marketing materials, or other group documents

- help an individual display main thoughts from a paper

- provide artwork or visuals for reports, marketing materials, etc.

So how do you add this powerful, meaningful visual to your next meeting? It's easy. Just go online to Wordle (http://Wordle.net), copy/paste in a little or a lot of text, and use the resulting imagery to show your group what matters most.

Wordle uses an algorithm to provide visual representation of word-frequency, i.e., the mostused words from your source-text show up in largest print. And you can tweak the cloud 
pictures with colors, layouts, and fonts. This can be a visually telling device that can help direct attention or to discern key topics upon which your group wishes to focus.

Has one of your youth teams or adult volunteer groups ever needed to come to agreement on an issue? When lots of discussion and input ensue, you can use Wordle in conjunction with an open-ended survey (e.g. free SurveyMonkey) to identify your key themes or topics. Here's how. Create the brief online survey and ask for open-ended responses prior to your meeting. Then cut and paste the responses into Wordle. The resulting word picture will be a great visual to show key points.

\section{Example}

Here is an example from a recent strategic planning session in Ohio for a civic organization:

Q 1: List 3 or 4 shared values that you believe (civic organization) members want to maintain and promote. In other words, what are 3 or 4 things that you believe are really important to folks?

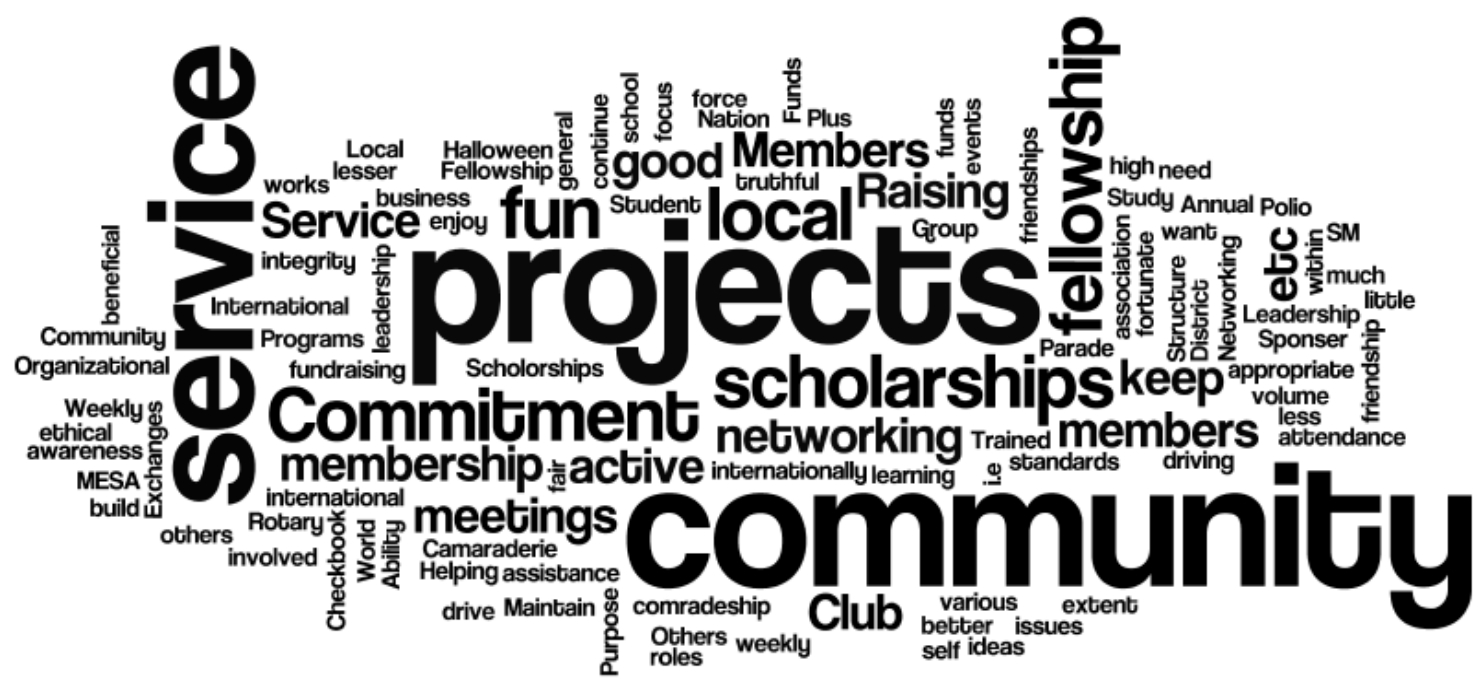

Q 2: Again, think about the mission or purpose of the (civic organization). What are the weaknesses? List 2 or 3 things we need:

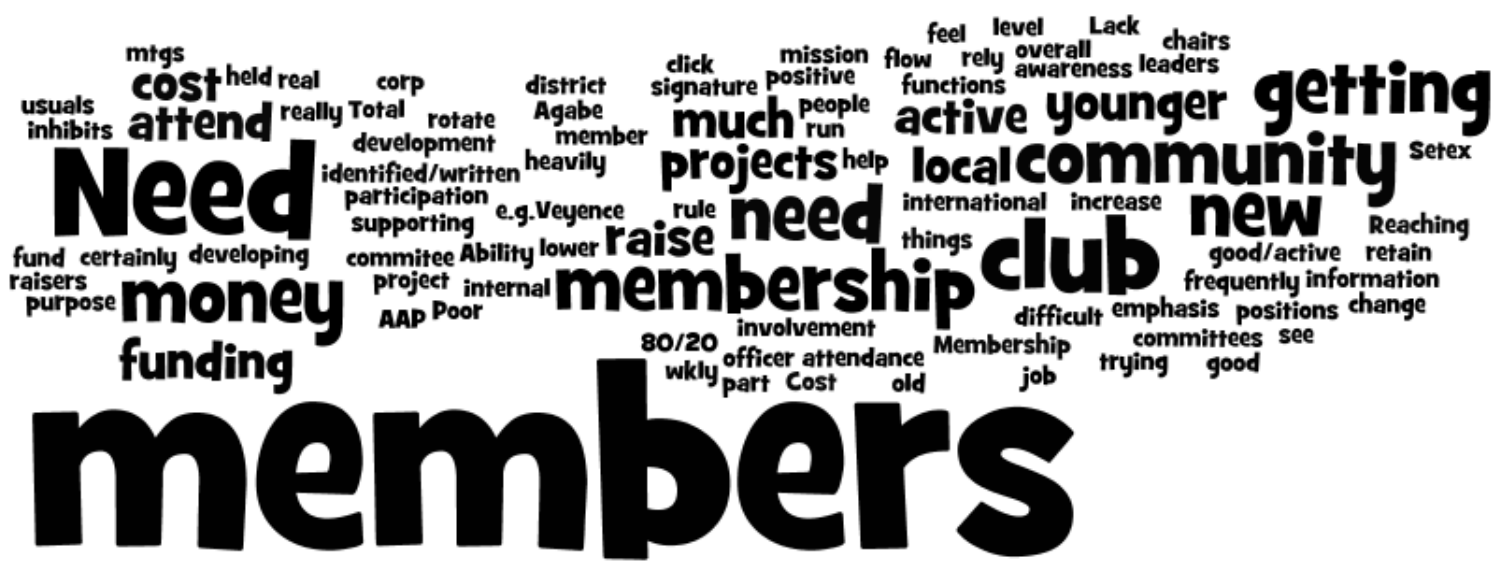


Q 3: Lastly, in thinking about the mission or purpose of the (civic organization), what are the opportunities for us?

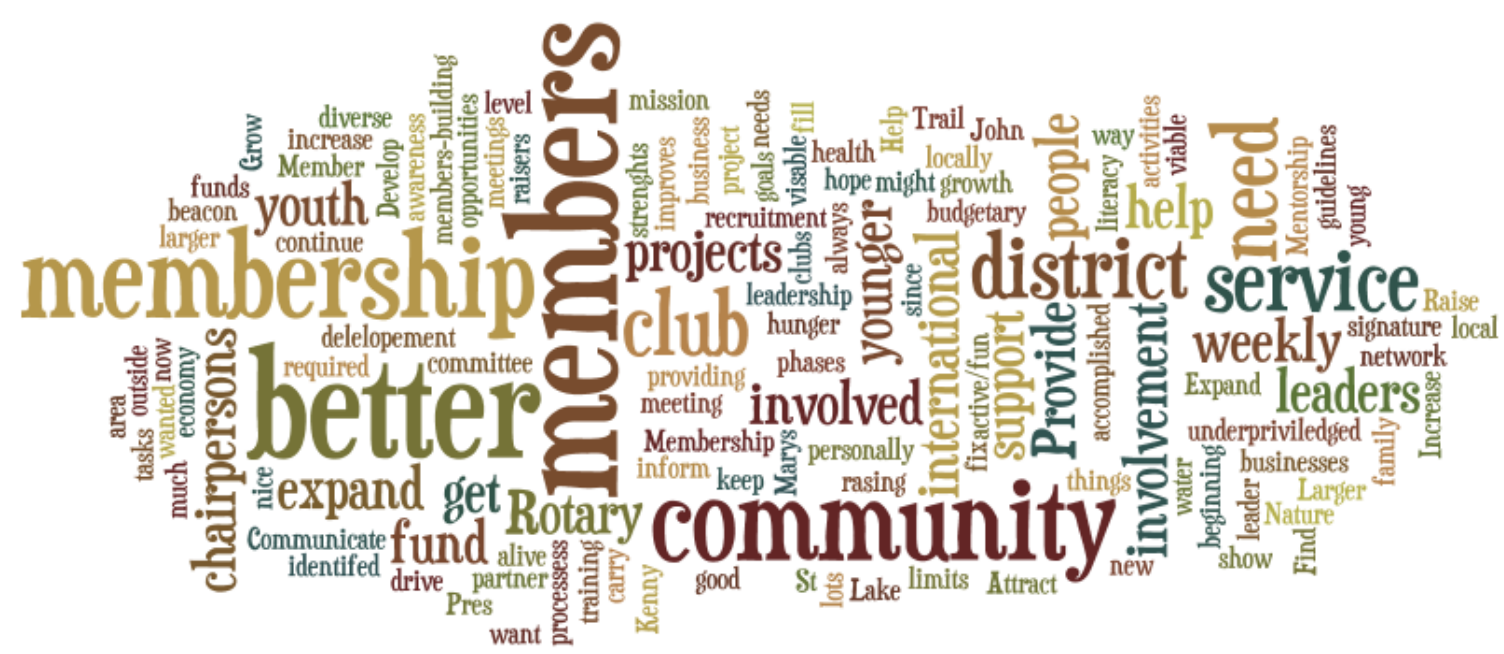

\section{References}

Wordle. (2012). Create your own word clouds from the text you provide. Retrieved from http://www.wordle.net/

(C) Copyright of Journal of Youth Development $\sim$ Bridging Research and Practice. Content may not be copied or emailed to multiple sites or posted to a listserv without copyright holder's express written permission. Contact Editor at: patricia.dawson@oregonstate.edu for details. However, users may print, download or email articles for individual use.

ISSN 2325-4009 (Print); ISSN 2325-4017 (Online) 